\title{
A genealogia de Michel Foucault e a história como diagnóstico do presente: elementos para a História da Educação
}

Michel Foucault's genealogy and history as diagnostics of the present: elements for Education's History

La genealogía de Michel Foucault y la historia como diagnóstico del presente: elementos para la Historia de la Educación

\author{
Haroldo de Resende \\ Universidade Federal de Uberlândia (Brasil) \\ https://orcid.org/0000-0001-9379-111X \\ http://lattes.cnpq.br/5363115483274501 \\ haroldoderesende@ufu.br
}

\section{Resumo}

Michel Foucault afirma que seus livros não são tratados de filosofia nem estudos históricos; mas que são, no máximo, fragmentos filosóficos em canteiros históricos, o que torna possível dizer que suas pesquisas se situam entre a reflexão filosófica e a prática historiográfica, sendo que o que está na perspectiva de sua história é o próprio presente. Trata-se de interrogar a irrupção dos acontecimentos que produziram nossa atualidade e investigar historicamente como e porque nos tornamos o que somos. Na abordagem da história pela genealogia, a análise foucaultiana recai sobre o saber em termos de estratégia e táticas de poder, o que implica situar o saber no embate das lutas e a verdade no jogo da disputa. O propósito aqui é remeter a discussão da história genealógica para o campo da educação, entendendo que ferramentas genealógicas podem fornecer elementos para a suspeição e o questionamento acerca não só da constituição da educação, mas também da própria noção de história, permitindo compreender a construção discursiva das memórias educacionais como efeitos de vontades de verdade.

Palavras-chave: Genealogia. História da educação. Diagnóstico do presente. 


\begin{abstract}
Michel Foucault affirms that his books are not philosophy treaties, neither historical studies, but are, at most, philosophical fragments in historical areas, which make it possible to say that his researches are situated between philosophic thinking and historiographical practice, being the present itself in the perspective of his history. It is about questioning the irruption of events that produced our present and historically investigating how and why we became who we are. In the genealogical approach of history on the field of education, the Foucauldian analysis falls upon knowledge, in terms of strategy and power tactics, implying in situating knowledge in the clash of struggles, the truth in the game of disputes. The purpose here is to take the discussion of genealogical history to the field of education, understanding that genealogical tools can provide elements to the suspicion and interrogation not only about the education constitution but also of the notion of history itself, allowing to understand discursive construction of educational memories as effects of real wills.
\end{abstract}

Keywords: Genealogy. History of education. Diagnosis of the present.

\title{
Resumen
}

Michel Foucault afirma que sus libros no son tratados como filosofía o estudios históricos; pero son, como máximo, fragmentos filosóficos en rincones históricos, lo que hace posible decir que sus investigaciones se sitúan entre la reflexión filosófica y la práctica historiográfica, de una manera que, lo que está en la perspectiva de su historia es el propio presente. Se trata de interrogar la irrupción de los sucesos que produjeron nuestra actualidad e investigar históricamente cómo y porqué nos volvimos lo que somos. En el abordaje de la historia por la genealogía, el análisis foucaultiana recae sobre el saber en términos de estrategia y tácticas de poder, lo que implica situar el saber en el embate de las luchas y la verdad en el juego de la disputa. El propósito aquí es remitir la discusión de la historia genealógica al campo de la educación, así se comprende que herramientas genealógicas pueden fornecer elementos para la suposición y el cuestionamiento acerca no solo de la constitución de la educación, sino que también de la propia idea de historia, lo que permite comprender la construcción discursiva de las memorias educacionales como efectos de ganas de verdad.

Palabras clave: Genealogía, Historia de la Educación, Diagnóstico del presente. 
Tudo para nós está em nosso conceito do mundo; modificar o nosso conceito do mundo é modificar o mundo [...]

Fernando Pessoa

Muitas vezes é na sombra do passado que se encontra a iluminação do presente.

Durval Muniz de Albuquerque Júnior

\section{Introdução}

Busca-se, neste artigo, desenvolver questões teórico-práticas acerca de construtos histórico-filosóficos de Michel Foucault, especialmente de suas formulações relativas ao projeto de uma história genealógica, a partir do qual o filósofo delineia não só uma concepção de história, mas também e, sobretudo, uma maneira de efetivar a história, libertando-a da noção de totalidade e continuidade evolutiva forjada como natural e, segundo a qual, a verdade seria objetiva e o trabalho do conhecimento deveria desvelar uma essência preexistente.

A partir disso busca-se articular marcos teóricos da genealogia ${ }^{1}$ foucaultiana com a efetivação da historia da educação, argumentando sobre a pertinência de se utilizar o referencial genealógico em empreendimentos no campo da história e historiografia da educação, uma vez que, incorporando noções genealógicas, a pesquisa e a produção do conhecimento em história da educação podem ganhar ampliações teórico-metodológicas que, certamente podem contribuir para o delineamento de outros contornos na compreensão das formas de organização e funcionamento da educação em nossa sociedade.

Com vistas à fundamentação conceitual, toma-se como base a partir da qual a discussão é sustentada, o texto intitulado Nietzsche, a genealogia e a história ${ }^{2}$, de Michel Foucault, escrito em 1971, a partir do qual são extraídas as principais noções que envolvem a proposição da história genealógica, cujo objetivo precípuo é insuflar saberes contra a pretensão de um bloco monolítico de saber que, em sua dominação acaba por produzir efeitos de poder na elaboração e legitimação dos conhecimentos históricos.

\footnotetext{
1 Genealogia é uma expressão que Foucault utiliza a partir de Nietzsche para designar um modo de abordagem da constituição histórica dos objetos, sem remetê-los a um começo solene, a um início fundamental.

2 Esse texto foi publicado no ano de 1971, pela Presses Universitaire de France (PUF), num livrohomenagem dedicado a Jean Hippolite, juntamente com textos de outros oito filósofos, dentre eles, Michel Serres, Georges Canguilhem e Jean Laplanche. No Brasil, fez parte, no ano de 1979, da coletânea Microfísica do poder, cujos textos foram traduzidos e organizados por Roberto Machado, tendo sido editada pela Editora Graal. No ano de 1994, integrou, na França, o Volume II da coleção Dit et écrits, que reúne conferências, entrevistas e outros textos de Foucault, até então esparsos e reunidos segundo o critério cronológico, sob direção de Daniel Defert e François Ewald e editada pela Gallimard, assim como em 2000, na versão brasileira dessa mesma coleção, agora pelo critério temático e com organização e seleção de textos de Manoel Barros da Motta. A versão do texto utilizado neste artigo é a que aparece em Microfísica do poder.
} 


\section{O marco genealógico de Michel Foucault}

No segundo momento do conjunto da obra de Foucault, justamente aquele chamado de genealogia ${ }^{3}$, há uma ampliação de seu campo de interesse, na medida em que busca mostrar a correlação entre discursos e práticas sociais, enfocando explicitamente a temática do poder articulada à das ordens e configurações do saber.

O termo genealogia ${ }^{4}$ é introduzido por Foucault no capítulo inicial do livro Vigiar $e$ punir: nascimento da prisão, obra seminal dessa fase genealógica. Segundo Machado, é nesse livro que seu sentido aparece formulado da forma mais clara. Eis duas passagens em que o termo aparece no livro Vigiar e punir:

Objetivo deste livro: uma história correlativa da alma moderna e de um novo poder de julgar; uma genealogia do atual complexo científico-judiciário onde o poder de punir se apóia, recebe suas justificações e suas regras, estende seus efeitos (Foucault, 1991, p.26).

Um pouco mais adiante, ainda no capítulo introdutório, Foucault evoca novamente a palavra genealogia: A história dessa microfísica do poder punitivo seria então uma genealogia ou uma peça para uma genealogia da 'alma' moderna (Foucault, 1991, p.31). Vêse, pois, que pelo contexto teórico-prático em que a expressão surge nas formulações de Foucault, sua conotação traz a importância que o poder, como correlativo da constituição dos saberes, assume em suas pesquisas.

\section{A história na perspectiva da genealogia de Michel Foucault}

A abordagem genealógica, restaurando o histórico, permite realizar efetivamente uma pesquisa histórica, na qual as noções ligadas ao conceito de origem assumem significados opostos ao das fundações originais que buscam marcos fundamentais para a comprovação da exatidão essencial das coisas e a perpetuação imóvel de uma identidade fixa no tempo e no espaço.

A genealogia faz a história dos percursos acidentais, dos atalhos, dos descaminhos, do disparate, provocando a suspensão da intemporalidade do sujeito, submetendo-o às práticas sociais e examinando o momento do surgimento e as condições específicas de possibilidades dos acontecimentos. Não se recua no tempo para o restabelecimento da imensidão de uma continuidade para além das dispersões da memória e do esquecimento. A genealogia não tem como tarefa a reconciliação com o passado, apontando que ele ainda está plenamente vivo no presente, secretamente movimentando-o, depois de ter demarcado desde o início um trajeto e uma forma definida. Na genealogia abandona-se a certeza das evoluções lineares, que vê as coisas como se elas guardassem em seu começo uma verdade única e pura. Pela genealogia, torna-se possível vislumbrar os acasos e intempéries das construções históricas.

\footnotetext{
3 Tornou-se usual a convecção de se estabelecer uma sistematização que caracteriza o conjunto da obra de Michel Foucault em três grandes fases, quais sejam, a arqueologia, e genealogia e a ética que correspondem ao período cronológico, dividido entre as décadas de 1960, 1970 e 1980, assim como a respectiva abordagem da questão da formação dos saberes, dos mecanismos de poder e da constituição do sujeito. A esse respeito, consultar o capítulo A trajetória de Michel Foucault do livro Foucault, simplesmente de Salma Tannus Muchail, assim como o capítulo Os três Foucault? ou a sempre difícil sistematização, que integra o livro Foucault e a educação, de Alfredo Veiga-Neto, cujas referências completas encontram-se ao final deste artigo.

${ }^{4}$ Cf. MACHADO, Roberto. Ciência e saber. A trajetória da arqueologia de Foucault. 2a ed. Rio de Janeiro: Graal, 1982. p. 187. Machado ressalta que a expressão aparece também no livro História da Sexualidade I: a vontade de saber assim como em cursos do Collège de France.
} 
Daí, para a genealogia, um indispensável demorar-se: marcar a singularidade dos acontecimentos, longe de toda finalidade monótona; espreitá-los lá onde menos se os esperava e naquilo que é tido como não possuindo história - os sentimentos, o amor, a consciência, os instintos; apreender seu retorno não para traçar a curva lenta de uma evolução, mas para reencontrar as diferentes cenas onde elas desempenharam papéis distintos; e até definir o ponto de sua lacuna, o momento em que eles não aconteceram [...] (Foucault, 1991, p.15).

Para Foucault, assim como propusera Nietzsche, a cor da genealogia é o cinza, justamente porque foge às claras evidências, às transparências, ao buscar apreender os apagamentos, aquilo que foi obscurecido por conhecimentos que se impuseram como únicos e definitivos.

$\mathrm{Na}$ genealogia busca-se ouvir a história e com isso se aprende que por trás das coisas não há nada que se possa traduzir em uma essência secreta e atemporal. O que existe são as coisas sem atributos essenciais, sem invenções construídas em torno de elementos estranhos a elas. Na gênese histórica não se encontra a identidade inédita e preservada da origem, mas o seu disparate, os seus desvios acidentais, a sua desavença. O começo histórico pertence às baixas extrações por ocupar-se dos deslizes, dos desníveis, da incerteza, do descomunal e por afastar-se dos pedestais meta-históricos construídos por significações ideais. Portanto, a genealogia insurge contra a pesquisa da origem. O genealogista necessita da história para conjurar a quimera da origem (Foucault, 1991, p.19).

Ao mesmo tempo, a pesquisa genealógica permite o reencontro do múltiplo nos acontecimentos que são tomados por um único aspecto como se sua formação tivesse se dado de maneira ímpar, sem dispersões. Na genealogia mantém-se a dispersão peculiar aos acontecimentos, a reconstituição dos acidentes, das fissuras, dos enganos, das falhas e errâncias que marcaram o nascimento daquilo que há de significativo em nossa existência.

$\mathrm{Na}$ genealogia não se faz um recuo no tempo para o restabelecimento de uma continuidade evolutiva que se prolonga até chegar ao presente, considerando-o como circunstância natural e inevitável do passado. Busca-se saber que na gênese do que somos e do que conhecemos não reside a verdade e o ser essencial e sim a exterioridade acidental. A genealogia permite restabelecer os jogos de dominação, nos quais se pode observar o estado de forças em que os acontecimentos são produzidos, uma vez que as forças, ao produzi-los, combatem entre si, marcam posições frente às adversidades e, quando se enfraquecem buscam se recompor a partir de sua própria fraqueza.

A tarefa da genealogia é fazer essa história, mostrando os deslocamentos, as quebras, as fraquezas, as substituições, os recomeços, dando visibilidade a outras possibilidades de interpretação que foram subsumidas pela prevalência de visões dominantes e totalizantes.

Foucault mostra as relações existentes entre a pesquisa genealógica e a história tradicional, que ele chama história dos historiadores (Foucault, 1991, p.26). A genealogia é nomeada como Wirkliche Historie ${ }^{5}$ ou história efetiva, cuja ferramenta é o sentido histórico que

não se apóia sobre nenhum absoluto. Ele deve ter apenas a acuidade de um olhar que distingue, reparte, dispersa, deixa operar as separações e as margens - uma espécie de olhar que dissocia e é capaz ele mesmo de se dissociar e apagar a unidade deste ser humano que supostamente o dirige soberanamente para seu passado (Foucault, 1991, p.27).

\footnotetext{
${ }^{5}$ Termo alemão, cunhado por Nietzsche, que designa, literalmente, história real.
} 
O sentido histórico se dirige em direção contrária à perspectiva supra-histórica da história dos historiadores, cujo olhar é totalizante, reconciliador dos deslocamentos passados, redutor do tempo a um só momento. O olhar da história tradicional é um olhar que se pretende objetivo e acredita na eternidade perene da verdade e numa consciência sempre igual a si mesma, é um olhar que permite o reconhecimento em toda parte, como se tudo refletisse o homem, é um olhar que mira um contínuo evoluir, sem obstáculos, quebras ou desvios.

Já o sentido histórico, praticando a Wirkliche Historie promove a reintrodução do devir em tudo o que se acreditava ser imortal no homem. A história 'efetiva' se distingue daquela dos historiadores pelo fato de que ela não se apóia em nenhuma constância: nada no homem - nem mesmo seu corpo - é bastante fixo para compreender outros homens e se reconhecer neles (Foucault, 1991, p.27). Utilizar genealogicamente a história, de maneira que o sentido histórico se livre da supra-história, significa fazer da história um uso que a liberte para sempre do modelo, ao mesmo tempo, metafísico e antropológico da memória. Trata-se de fazer da história uma contramemória e de desdobrar consequentemente toda uma outra forma do tempo (Foucault, 1991, p.33).

O genealogista ao invés de venerar os grandes vultos, suas obras, suas criações, perpetuando a sua presença, erguendo uma história monumental (Foucault, 1991, p. 34), parodia essa história e carnavaliza o tempo realocando o aparecimento incessante das máscaras, justamente para que o homem se irrealize em diversas identidades retornadas. A genealogia é a história como um carnaval organizado (Foucault, 1991, p. 34). A genealogia traz a pluralidade e a diversidade que se desdobram em várias outras identidades que disputam entre si. O que a história faz não é descobrir uma identidade submergida, de prontidão para o seu aparecimento; mas, mostra a complexidade e multiplicidade de aspectos, às vezes díspares.

A história genealogicamente dirigida, não tem por fim reencontrar as raízes de nossa identidade, mas ao contrário, se obstinar em dissipá-la; ela não pretende demarcar o território único de onde nós viemos, essa primeira pátria à qual os metafísicos prometem que nós retornaremos, ela pretende fazer aparecer todas as descontinuidades que nos atravessam (Foucault, 1991, p. 34-35).

Não se busca o reconhecimento de continuidades em que se encontra o começo de nosso presente, num processo contínuo de preservação; ao contrário, a genealogia propicia a quebra de nossas identidades, mostrando múltiplas possibilidades e a heterogeneidade, arrancando a máscara de nosso eu (Foucault, 1991, p. 35), permitindo-nos outras identidades.

Foucault, desse modo, formula o projeto de uma história genealógica, estabelecendo novas noções para a abordagem do tempo e do espaço históricos, dando novas visões para as reminiscências, para as continuidades e para o próprio conhecimento. A realidade se desfaz em paródias, as identidades se fragmentam e a verdade é destroçada. O acontecimento, dessa forma, perde sua linearidade contínua, pois a genealogia se apodera de suas regras, de suas forças, da inversão dessas forças que se voltam contra quem as utiliza, enfraquecendo o vigor das dominações no movimento do jogo da história nos acasos da luta ${ }^{6}$.

A genealogia é, assim, direcionada para o estudo das formas de saber atravessadas por relações de poder. Portanto, pode-se entender a abordagem genealógica de Foucault como a investigação histórica das manifestações, tecnologias e estratégias de poder em suas relações com o saber. Em suma, a genealogia disponibiliza chaves de interpretação histórica das formas e condições políticas em que são produzidos e difundidos os conhecimentos.

\footnotetext{
${ }^{6}$ Cf. FOUCAULT, Michel. Nietzsche, a genealogia e a história, 1992. p. 28. / Cf. FOUCAULT, Michel. "Nietzsche, la généalogie, l'histoire", 1994, p. 148.
} 
O que entendo por genealogia é, em simultâneo, a razão e o objetivo da análise desses discursos enquanto acontecimentos; e o que tento mostrar é como esses acontecimentos discursivos determinaram, de certa maneira, aquilo que constitui o nosso presente e que nos constitui a nós próprios, o nosso conhecimento, as nossas práticas, o nosso tipo de racionalidade, as nossas relações com nós próprios ou com os outros (Foucault, 2017, p. 105).

\section{Noções da genealogia na história da educação e a atualidade}

Ao incorporar noções e categorias genealógicas, a pesquisa e a produção do conhecimento em história da educação podem ganhar contornos teórico-metodológicos que, certamente trazem, senão exatamente novas, outras perspectivas para a compreensão das formas de organização e funcionamento da ordem educacional em nossa sociedade.

A questão talvez seja a de percebermos que repertórios teóricos temos hoje à nossa disposição, de que arsenais conceituais críticos dispomos para enfrentarmos um mundo que também tornou-se muito mais sofisticado, opaco e complexo. Nesse contexto precisamos saber como poderemos usar as metodologias existentes, desdobrá-las em outras tantas e como poderemos aproximar os resultados produzidos no interior de nossa área interdisciplinarmente com os de outras áreas, de modo a enriquecermos nossa compreensão da atualidade e das tarefas que ainda são possíveis (Rago, 2002, p. 272).

Trata-se de questionar noções espaciais e temporais, colocar em suspeição conceitos cristalizados de objeto, de sujeito, de aprendizagem, de escola, de escolarização, de infância, de juventude, de ensino, de educação; enfim, dos próprios conceitos de história e de historiografia, com os quais operamos. Tal questionamento nos deixa alertas em relação à própria construção da verdade, à própria escrita da história, particularmente, da educação, como sendo algo que se constitui, ela mesma, historicamente por categorias específicas e datadas que legitimam determinado ponto de vista.

As formas que os objetos históricos adquirem só podem ser explicadas pela própria História. É vasculhando as camadas constitutivas de um dado saber, de um dado acontecimento, de um dado fato, que podemos apreender o movimento de seu aparecimento, aproximando-nos do momento em que foi ganhando consistência, visibilidade e dizibilidade, foi emergindo como as duras conchas emergem do trabalho lento de petrificação do lamaçal do mangue (Albuquerque Júnior, 2000, p. 120).

Embora os fatos, os acontecimentos, os objetos histórico-educacionais sejam materiais deixados pelo passado e constituam registros que buscam cristalizar o sentido de momentos e de experiências, o historiador da educação deverá lhes lançar novos olhares, buscando perceber quebras, fissuras, lacunas e dispersões que os constituíram como tal. Há, desse modo, uma recusa pela busca da origem como começo solene, espaço em que o sentido profundo do passado se esconderia como essência de onde tudo deriva, numa linha progressiva, cuja culminância se encontra no tempo presente. O projeto da história genealógica propõe mostrar que é um mito a objetividade histórica que busca o sentido profundo e secreto da verdade, recolhendo numa totalidade hermética a diversidade do tempo. 
A história da educação, na perspectiva genealógica busca perceber a necessidade e as contingências de construções discursivas determinadas que sustentam relatos que descrevem o que e como eram no passado os saberes, as práticas e os sujeitos na composição dos processos educativos. Desse modo, entende-se que os objetos definidos para o conhecimento da história da educação foram transformados como tais num dado momento e numa dada conjunção de forças e narrativas, o que permite dizer que cada objeto histórico-educacional é, antes de tudo, talhado como objeto político.

Os contornos que damos ao passado, as regiões deste que iluminamos, os sujeitos que apanhamos entre poeira e fazemos novamente se encenarem, as tramas que pensamos ouvir no desvão dos arquivos, atendem a problemas e embates do nosso tempo, em que estão mergulhadas nossas próprias vidas. Nada nos chega do passado que não seja convocado por uma estratégia, armado por uma tática, visando atender alguma demanda do nosso próprio tempo (Albuquerque Júnior, 2000, p. 123).

Tendo no horizonte de análise a utilização de ferramentas genealógicas na investigação de objetos do amplo espectro de análise do campo educacional, seja na abrangência de políticas educacionais, projetos educativos, programas governamentais e legislações, seja no recorte da instituição escolar com seus processos formativos, práticas pedagógicas, regulamentos, normativas, assim como nas inumeráveis possibilidades de emergência de objetos históricos que podem surgir na seara da educação, é oportuno dizer que o trabalho do historiador que se propõe a narrar a educação, deve se pautar por um inventário de questões que perscrutem tanto a educação, como a história, como campos atravessados por relações de poder. Como foi possível o surgimento de tal objeto histórico-educacional? Que história se narra de tal objeto histórico-educacional? Que concepção de educação se busca perpetuar na memória? O que possibilita a idéia de naturalidade a algo produzido nas tramas históricas do campo educativo? O que fez a educação torna-se o que é? É possível que a educação se torne algo diferente? Que história da educação está se escrevendo? Que verdades estão sendo instituídas com a narrativa histórico-educacional? Que sujeitos são postos em evidência nessa história?

O trabalho do historiador da educação balizado por interrogações desse tipo, o coloca num patamar de suspeição, de questionamento acerca não só da educação, mas da própria noção de história e historiografia, permitindo outras formas de enxergar a constituição da educação na configuração da sociedade, assim como a instituição de verdades sobre a educação na memória educacional por efeitos de vontades, cristalizando narrativas que fazem prevalecer determinados pontos de vista e acabam por obscurecer o surgimento de outas perspectivas.

As dimensões dadas ao passado, os lugares privilegiados desse passado, os sujeitos escolhidos para (nova) visibilidade, os discursos ouvidos das fontes, acabam respondendo a problemas e questões do nosso presente e dizem respeito ao nosso modo de viver. O que nos vem do passado é atravessado por estratégias e é alcançado por táticas que buscam atingir nossas próprias demandas atuais.

Se o trabalho da história está em remontar ao passado, conferindo-lhe alguma inteligibilidade, em narrativas que o descrevem, o analisam e o perpetuam mantendo-o na coerência de um discurso, pode-se, ao mesmo tempo, afirmar que no empreendimento de Michel Foucault naquilo que se refere à história genealógica, o que é feito é o estabelecimento de uma interrogação histórico-filosófica sobre o presente.

De maneira que o filósofo recorre a acontecimentos do passado para interrogar a atualidade, a nossa modernidade. Para problematizar a questão da forma prisão, por exemplo, 
ele recua aos suplícios e outros modos de punição da idade clássica para mostrar que a prisão é uma invenção bem mais recente do que se ousa imaginar e que nem sempre a pena, por excelência, no jogo da sociedade punitiva, foi o encarceramento. Do mesmo modo, quando ele aborda o tema da loucura, seu objetivo não foi construir uma narrativa das diferentes maneiras de ser louco ou de participar da sociedade sendo louco, ao longo de uma temporalidade, mas dar a ver a mutabilidade da loucura, retirando-a de toda e qualquer obviedade natural e mostrando-a como objeto fabricado por práticas discursivas e não discursivas em relações de saber-poder.

No texto $O$ que são as luzes?, publicado em 1984, Foucault aborda, uma vez mais, o clássico opúsculo de Kant, Resposta à pergunta: o que é a Aufklärung ? ${ }^{7}$, desta feita para destacar diferentes aspectos que o leva a realizar uma análise que aponta para o diagnóstico do presente e o entendimento da modernidade como uma atitude e não um período histórico com recorte temporal determinado, de modo que a atitude crítica é concernente a uma forma de relação com a atualidade. De tal sorte que é o problema do presente, da atualidade é que entra em questão, é aquilo que acontece nos dias de hoje, sendo que não se busca a compreensão do presente a partir de uma totalidade ou de um futuro a ser realizado, mas se introduz a diferença de hoje em relação ao passado.

Tanto a educação como a história são produzidas em campos de disputas, de embates, de relações de força, de maneira que trabalhar com a descontinuidade, com a destruição dos pontos fixos, com a quebra das identidades, com a inversão das forças, com a desconstrução dos discursos, com a instauração da diferença, pode possibilitar a percepção de que as verdades são construções crivadas de vontades e estratégias que acabam por elaborar versões cuja marca é justamente o caráter interessado.

Não há um único caminho ou um tempo unificado, iguais a si mesmos, sem curvas e perigos ou sem vácuos e descontinuidades; ao contrário, há vários caminhos com diversos atalhos e errâncias, há diferentes temporalidades com quebras e reticências, por isso, talvez seja correto dizer que o caminho a ser seguido pelo historiador da educação seja o próprio encontro dos descaminhos ou dos caminhos traçados fora de qualquer teleologia, assim como o tempo a ser marcado seja o das múltiplas temporalidades que atravessam o presente e nos torna o que somos. Talvez o objetivo hoje em dia não seja descobrir o que somos, mas recusar o que somos (Foucault, 1995, p. 239), o que nos posiciona naquilo que Foucault chama de ontologia da atualidade, de diagnóstico do presente, pois é na recusa do que somos que podemos nos situar na atualidade do campo das experiências possíveis.

\section{Referências}

ALBUQUERQUE JR., Durval Muniz de. "Um leque que respira: a questão do objeto em história". In: PORTOCARRERO, Vera \& BRANCO, Guilherme Castelo. Retratos de Foucault. Rio de Janeiro: Nau, 2000.

FOUCAULT, Michel. "Nietzsche, a genealogia e a história". In: FOUCAULT, Michel. Microfísica do poder. Tradução: Roberto Machado. 10ª ed. Rio de Janeiro: Graal, 1992, p. 15-37.

FOUCAULT, Michel. Vigiar e Punir: nascimento da prisão. Tradução: Lígia M. P. Vassalo. $9^{a}$ ed. Petrópolis: Vozes, 1991.

\footnotetext{
${ }^{7}$ Foucault aborda em diferentes momentos esse opúsculo de Kant, escrito em 1784, como resposta à questão $O$ que é a Aufklärung? proposta por um jornal, sendo que, ao lado de $O$ que são as luzes?, o outro texto mais significativo e talvez mais importante, em que ele analisa as proposições kantianas é $O$ que é a crítica?, resultado de uma conferência proferida em 1978 na Société Française de Philosophie.
} 
FOUCAULT, Michel. "O sujeito e o poder". In.: RABINOW, Paul e DREYFUS, Hubert. Michel Foucault: uma trajetória filosófica - para além do estruturalismo e da hermenêutica. Tradução: Vera Porto Carrero / Introdução traduzida por Antônio Carlos Maia. Rio de Janeiro: Forense Universitária, 1995.

FOUCAULT, Michel. O que é a crítica? seguido de A cultura de si. Tradução: Pedro Elói Duarte. Lisboa: Edições Texto \& Grafia, 2017.

MACHADO, Roberto. Ciência e saber. A trajetória da arqueologia de Foucault. Rio de Janeiro: Graal, 1982.

MUCHAIL, Salma Tannus. "A trajetória de Michel Foucault”. In. MUCHAIL, Salma Tannus. Foucault, simplesmente. São Paulo: Loyola, 2004. p. 9-20.

PESSOA, Fernando. Livro do desassossego. Porto: Assírio \& Alvim, 2014.

RAGO, Margareth. "Libertar a história”. In: RAGO, Margareth; ORLANDI, LUIZ Lacerda \& VEIGA-NETO, Alfredo. Imagens de Foucault e Deleuze: ressonâncias nietzschianas. Rio de Janeiro: DP\&A, 2002.

VEIGA-NETO, Alfredo. “Os três Foucault? ou a sempre difícil sistematização". In.: VEIGANETO, Alfredo. Foucault e a educação. Belo Horizonte: Autêntica, 2004. p. 41-49. 